\title{
EDITORIAL
}

\section{ECG - ARE WE DOING IT RIGHT?}

\author{
PROFESSOR ABDUL WADUD CHOWDHURY
}

Electrocardiography (ECG or EKG from Greek: kardia, meaning heart) is the recording of the electrical activity of heart. Traditionally it is a form of transthoracic interpretation of electrical activity of the heart over a period of time as detected by electrodes attached to the surface of the skin and recorded or displayed by a device external to the body. The recording produced by this non invasive procedure is termed as electrocardiogram (also ECG or EKG). In the century since the invention of the string galvanometer by William Einthoven. ${ }^{1}$ The electrocardiogram (ECG) has become the most commonly conducted cardiovascular diagnostic procedure and a fundamental tool of clinical practice ${ }^{2,3}$ It is indispensable for the diagnosis and prompt initiation of therapy in patients with acute coronary syndrome and is the most accurate means of diagnosing cardiac conduction disturbances and arrhythmias. It can help in recording electrolyte abnormalities, particularly of serum potassium and calcium and permit the detection of some forms of genetically mediated or structural cardiac abnormalities. The ECG is routinely used to screen individuals employed in high-risk occupations and in pre-operative assessment of patients undergoing non-cardiac surgery. ${ }^{4}$

As a first line diagnostic tool, healthcare providers at different levels of training and expertise frequently find it imperative to have the ability to interpret ECGs. However, a high rate of misinterpretation has been noted among non-specialized physicians especially among trainees. ${ }^{5}$ The US Preventive Services Task Force do not recommend either the ECG or any other cardiac imaging procedure as a routine screening procedure in patients without symptoms and at low risk for coronary heart disease. ${ }^{6,7}$ This is because overuse of the procedure is more likely to supply incorrect supporting evidence for a non-existent problem than to detect a true problem. ${ }^{7}$ Tests that falsely indicate the existence of a problem are likely to lead to misdiagnosis, the unnecessary recommendation of invasive procedure or overtreatment. ${ }^{7}$ Because of its broad applicability, the accurate recording and precise interpretation of the ECG are critical.

At present most of the ECGs are recorded by digital automated machines equipped with software that measures ECG intervals and amplitudes and provides a virtually instantaneous interpretation. However, different automated systems may have different technical specifications that result in significant differences in the measurement of amplitude, intervals and diagnostic statement. ${ }^{4}$ In Bangladesh a personal survey in the chamber of a physician showed that nearly $10 \%$ the ECGs show some type of technical errors like limb lead switching, improper voltage standardization and improper precordial lead placement induced errors. When precordial electrodes are positioned without reference to the underlying bony landmarks, the placement pattern often is vertical in orientation. Mapping data document profound alterations in wave forms that can result from precordial electrode misplacement. ${ }^{8}$ A common error is superior misplacement of $V_{1}$ and $V_{2}$ in the second or third intercostal space. This can result in reduction of initial $\mathrm{R}$-wave amplitude in these leads, approximating $0.1 \mathrm{mV}$ per inter space, which can cause poor R-wave progression or erroneous signs of anterior infraction. 9 Technicians and other medical personnel responsible for the recording of ECGs should have periodic retraining in skin preparation, proper electrode positioning and proper patient positioning. 
A 1985 study by European CSE group demonstrated that measurement differences among 10 standard ECG systems could be large enough to alter diagnostic conclusion. ${ }^{10}$ It has been shown that overall the percentage of ECGs correctly classified by the automated computer programs (median 91.3\%) was lower than that for the cardiologists (median 96.0\%), where as important differences in overall accuracy were found between different algorithms. ${ }^{11}$ It is therefore evident that physicians over-reading and confirmation of computer based ECG is required. ${ }^{4}$

In Bangladesh, given the untested quality of the available ECG machines, the lack of training of the personnel responsible for doing the procedure and the lack of expertise in interpreting the ECG by the general physicians made this cost-effective, efficient diagnostic tool to lose much of its usage. Even in specialization examinations the level of expertise in proper interpretation of the ECGs by the future-specialists appear not very satisfactory (personal communication with senior examiners).The whole situation is, therefore, quite alarming for our medical academic community. Einthoven won the Nobel Prize in 1924 for inventing the Electrocardiogram machine. Let us glorify his legacy by properly doing, understanding and using the ECG.

\section{References:}

1. Einthoven W. Galvanometrische registration van het menschelijk electrocardiogram. In: Herinneringsbundel Professor S. S. Rosenstein. Leiden. Netherlands: Eduard Ijdo; 1902:101-106

2. Kigfield P. The Centennial of Einthoven electrocardiogram. J Electrocardiol. 2002; 35(suppl): 123-129

3. Fye WB. A history of the origin, evolution, and impact of electrocardiography [published correction appears in Am J Cardiol.1995;76:64]. Am J Cardiol. 1994; 73:937-949.
4. Kligfield P, Gettes LS, Baiely JJ et al. Recommendations for the standardization and interpretation of the electrocardiogram Part1: The Electrocardiogram and its Technology: A Scientific statement from the American Heart Association Electrocardiography and Arrhythmias Committee, Council on Clinical Cardiology; the American College of Cardiology Foundation; and the Heart Rhythm Society Endorsed by the International Society for Computerized Electrocardiography. Circulation.2007;115;13061324.

5. Salerno SM, Aguirre PC, Waxman HS. Training and competency evaluation of interpretation of 12lead electrocardiograms: Recommendations from American College of Physicians. Ann Intern Med 2003;138(9):747-50.

6. Moyer VA. "Screening for coronary heart disease with electrocardiography: U.S. Preventive Services Task Force recommendation statement." Ann Inter Med 2012;157(7):512-8.

7. Consumers Reports; American Academy of Family Physicians (April 2012),"EKGs and exercise stress test :When you need them for heart disease-and when you don't, Choosing Wisely" :an initiative of the ABIM Foundation (Consumer Reports).

8. Schijvenaars BJ, Kors JA, van Herpen G, Kornreich F, van Bemmel JH. Effect of electrode positioning on ECG interpretation by computer. $J$ Electrocardiol. 1997;30:247-256.

9. Zema MJ, Kligfield P.ECG poor R-wave progression: review and synthesis. Arch Intern Med. 1982:142:1145-1148.

10. Willems JL, Arnauld P, Bemmel JH et al. Assessment of the performance of electrocardiographic computer programs with the use of a reference database. Circulation 1985; 71: 523534.

11. Willems JL,Abreu-Lima c,Arnauld P ,van Bemmel JH ,Brohet C , Degani R, Denis B, Gehring J, Graham I, van Herpen G, Machado H,Macfarlane PW, Michaelis J, Moulop[oulos SD, Rubel P, Zyweitz C. The diagnostic performance computer programs for the interpretations of electrocardiograms. N Engl J Med. 1991;325:1767-1773. 